\title{
ESBOZO DE LA APROPIACIÓN POLÍTICA Y JURÍDICA DEL BIOLOGICISMO DETERMINISTA EN LA PRIMERA MITAD DEL SIGLO XX EN COLOMBIA
}

\author{
Carlos Mario García Ramírez" \\ Sergio Andrés Giraldo Galeano
}

Fecha de recibido: 17 de julio de 2014

Fecha de aprobado: 29 de octubre de 2014

Artículo de Investigación

Forma de citación: García, C. \& Giraldo, S. (2015). Esbozo de la apropiación política y jurídica del biologicismo determinista en la primera mitad del siglo XX en Colombia. Revista Prolegómenos. Derechos y Valores, 18, 35, 81-102

\section{Resumen}

Las condiciones de posibilidad de la circulación y apropiación de las ideas biologicistas, higienistas y deterministas en la Colombia de la primera parte del siglo XX, se pueden entender desde la importancia que cierto sector de la élite intelectual, que se formó mayoritariamente en Europa o en contacto con ella, le dio en sus distintos discursos al tema de la raza.Primero desde la medicina entendida en su más amplio espectro como un saber y, después, desde la política y el derecho; periodo en el cual, se identifica el protagonismo de la medicina en reformas jurídicas o de expedición de normas para lo que la sociedad demandaba en ese momento en la perspectiva del control social sobre individuos y población en general.

\section{Palabras clave:}

Biologicismo, higienismo, determinismo, Colombia primera parte siglo XX.

\section{OUTLINE OF POLITICAL AND LEGAL APPROPRIATION OF DETERMINISTIC BIOLOGICISM IN THE FIRST HALF OF THE TWENTIETH CENTURY IN COLOMBIA}

\begin{abstract}
The conditions of possibility of circulation and appropriation of biologicist, hygienist and deterministic ideas in Colombia in the early twentieth century can be understood from the importance that a certain sector of the intellectual elite, which was mainly educated in Europe

* Artículo derivado del proyecto de investigación "Función prescriptiva del derecho en el tratamiento político de la vida durante las dos últimas décadas en Colombia", del cual ambos autores son co-investigadores. Está adscrito al Grupo de Investigación Polemos de la Corporación Universitaria de Sabaneta.

** Docente e investigador de la Facultad de Derecho de la Corporación Universitaria de Sabaneta.Miembro del Grupo Polemos-línea conocimiento y sociedad- de la misma institución.Correo electrónico:cgarciar5@gmail.com

*** Docente e investigador de la Facultad de Derecho de la Corporación Universitaria de Sabaneta.Miembro del Grupo Polemos-línea conocimiento y sociedad- de la misma institución. Correo electrónico:sergiogaleano@yahoo.es
\end{abstract}


or in contact with it, gave through its various discourses to the race issue. First, from medicine, understood in its broadest spectrum as a knowledge, and then from politics and law; period in which it is identified the role of medicine in legal reforms or in issuance of rules for what society demanded at that time, in the perspective of social control over individuals and the population, in general.

\section{Keywords:}

Biologicism, hygienism, determinism, Colombia first half of the twentieth century.

\section{ESBOÇO DA APROPRIAÇÃO POLÍTICA E JURÍDICA DO BIOLOGICISMO DETERMINISTA NA PRIMEIRA METADE DO SÉCULO XX NA COLÔMBIA}

\section{Resumo}

As condições de possibilidade da circulação e apropriação das ideias biologicistas, higienistas e deterministas na Colômbia da primeira parte do século XX, podem-se entender da ótica da importância que certo setor da elite intelectual formada maioritariamente na Europa ou em contato com ela impôs à questão da raça, nos seus diversos discursos. Primeiro, do olhar da medicina entendida em seu mais amplo espectro como um saber e, depois, na política $e$ no direito. No referido período identifica-se, ainda, o protagonismo da medicina no âmbito das reformas jurídicas ou de produção normativa para tudo que a sociedade demandava na perspectiva do controle social sobre os indivíduos e a população em geral.

\section{Palavras-chave:}

Biologicismo, higienismo, determinismo, Colômbia primeira metade do século XX.

Ya que en verdad debemos parte de nuestra vida al medio social que nos sustenta está bien en justicia que contribuyamos, según el alcance de nuestras facultades, al mejoramiento de ese medio[...]

La armonía en que progresa la vida social nos trae, con el beneficio de un engranaje en que podamos actuar provechosamente, un legado de instituciones políticas y de principios definidos en la esfera intelectual y moral, que es como la herencia de la raza. Conservarlo es no solamente una necesidad vital sino también un deber de gratitud.

Luis López de Mesa, s.f.

\section{INTRODUCCIÓN}

Compuesto de tres partes, este artículo tiene como objetivo, analizar las ideas biologicistas y deterministas en la primera mitad del siglo XX en Colombia, profesadas por pensadores pertenecientes a lo que aquí se llamó la "Generación del Centenario"1, para inferir cómo circularon y

1 Así se calificó a la generación que vivió de forma directa la celebración del primer centenario de la independencia de la Nueva Granada (hoy República de Colombia) en 1910. Le tocó los hechos ocurridos el 13 de marzo de 1909, conocidos como el levantamiento "sin sangre" que terminó con el derrocamiento del entonces presidente Rafael Reyes (1849-1921). La importancia de ello radicó, según López de Mesa (1934), en que gracias a él, se inicia de verdad, la adultez de Colombia como 
fueron apropiadas, directa o indirectamente, en los ámbitos político y jurídico. Esta generación que reclamaba para sí, el papel de partera de una nueva nacionalidad, civilizada ${ }^{2}$ y no bárbara, ilustrada y no guerrerista.

Nuestra preocupación surge del "problema" que representó en la primera parte del siglo XX, para cierto sector de la intelectualidad colombiana (médicos, políticos y abogados)-formada casi en su totalidad en Europa o en contacto permanente con su cultura-, la circulación y la apropiación de las ideas biologicistas y deterministas, básicamente de corte spenceriano y hegeliano, que tuvieron un protagonismo innegable.

Luego, se hará una somera lectura jurídica del biologicismo o como lo llaman algunos, racialismo. El para qué de esta lectura, quiere mostrar cómo ese pensamiento se convirtió en condición de posibilidad de reformas jurídicas o de expedición de normas para lo que socialmente se demandaba en ese momento. Por ejemplo, sus aportes a la legislación educativa, sanitaria y penal de corte peligrosista o de prevención social, en el contexto de lo que se denominó allá y aquí, el derecho penal de autor.

Por último, se inferirán algunas conclusiones sobre lo dicho y las perspectivas sobre lo que se pudo haber dicho después o se dice actualmente.

una República. Es un movimiento crítico y de nostalgia. Lo primero, porque cuestiona la realidad del país en el gobierno del general Reyes. Lo segundo, porque ante la pérdida de Panamá -antigua provincia de Colombia en 1903, apoyada por la administración de los Estados Unidos- y el advenimiento de la Primera Guerra Mundial en 1914, se cierne sobre este grupo de intelectuales una especie de escepticismo sobre el futuro de América Latina y de Colombia, entre otras cosas, por el bloqueo que les impediría viajar a Europa y a Estados Unidoscon la misma facilidad y continuidad con la que lo hacían, lo que a la postre no fue óbice para que el espíritu "civilizador" europeizante se impusiera y autores como Herbert Spencer (1820-1903), calaran tan hondo como lo hicieron, gracias a las tertulias en casas o lugares de encuentro de intelectuales en Bogotá y en las aulas universitarias.

2 Civilización o barbarie, dicotomía ideologizante, usada a lo largo de la historia en distintos contextos y con propósitos varios, pero siempre recalcando la
Es de aclarar que el presente artículo es producto de la investigación de enfoque cualitativo, modalidad documental, sobre "Función prescriptiva del derecho en el tratamiento político de la vida durante las dos últimas décadas en Colombia”, financiada por la Corporación Universitaria de Sabaneta y adscrita al Centro de Investigaciones de esa misma institución.

\section{A. Las ideas biologicistas y deterministas en Colombia}

Las condiciones de posibilidad de la circulación y apropiación de las ideas biologicistas, higienistas y deterministas en la Colombia de la primera parte del siglo XX, se pueden entender desde el protagonismo que cierto sector de la élite intelectual, que se formó mayoritariamente en Europa o en contacto con ella, le dio en sus distintos discursos al tema de la raza. Primero desde la medicina, entendida en su más amplio espectro como un saber y, después, desde la política y el derecho, periodo en el cual se podría hablar de la medicina como ciencia política.

Corrientes de pensamiento como el liberalismo político anglosajón, el positivismo cientificista del siglo XIX, el evolucionismo biológico de Herbert Spencer (1820-1903) y de Oswald Spengler (1880-1936) y el idealismo hegeliano, serán la

superioridad de alguna idea, condición, raza, cultura o territorio sobre otros.La usó Aristóteles (384 a.C322 a.C) para descalificar como bárbaros a los que no hablaban griego; la iglesia cristiana para arremeter contra los moros; los racionalistas modernos contra los defensores del ancien régime; las potencias europeas decimonónicas como instrumento imperialista sobre las colonias africanas, asiáticas y americanas con su discurso de las geografías binarias (tierras prósperas vs. tierras salvajes); Domingo Faustino Sarmiento (1845) y Juan Bautista Alberdi (1852) en Argentina y Luis López de Mesa (1926) en Colombia, para proponer el lavado de cerebro y la transfusión de sangre que permitiera a las gentes de sus respectivos países, acceder al progreso guiados por los EE. UU. e Inglaterra y los nórdicos, respectivamente; y en 1997 Samuel Huntington (19272008) para referirse a la división geopolítica entre Occidente y Oriente, enfatizada básicamente, luego de los atentados del 11 de septiembre de 2001 perpetrados contra el WorldTrade Center en Nueva York. 
base doctrinaria de toda esa generación de médicos convertidos en políticos. Spencer (1850), sintetiza el evolucionismo del que López de Mesa es un expositor en Colombia, coincidiendo en la preocupación por la historia de las civilizaciones y el destino de los pueblos, tema al que el profesor prestará atención en su obra.

Ubicado en la mitad ambigua de los extremos de la controversia "científica" sobre la raza colombiana, es contrario a la tradición higienista más radical, encabezada por el también médico, Miguel Jiménez López y su tesis de la degeneración física, psíquica y moral del colombiano.

Para este, la primera de estas degeneraciones se expresaba en baja estatura, disimetrías cranianas, enanismo, baja longevidad, altas tasas de tuberculosis, lepra y cáncer; la segunda de ellas en continua imitación intelectual y consecuente falta de ideas propias, impaciencia, emotividad e inestabilidad mental que provocaban constantes guerras civiles, reformas constitucionales y una alta tasa de criminalidad, suicidio y locura; y la tercera degeneración, la moral, se expresaba en el sectarismo, el fanatismo, la prostitución, la criminalidad infantil, la toxicomanía y las perversiones sexuales. Además, estos signos de degeneración estaban claramente localizados geográfica y socialmente en una escala, en la cual la distancia de los centros urbanos, el alejamiento fenotípico del modelo blanco y la pobreza eran equivalentes a una mayor degeneración.

Jiménez López no solo enunció los signos de degeneración sino que también mostró sus causas y planteó soluciones: el alcoholismo, la miseria, la alimentación y la educación inadecuadas debían ser resueltos con acertadas políticas sanitarias, educativas y económicas. No obstante, estas medidas

3 Consultar más precisamente las ideas deterministas de Hegel en la introducción general de sus Lecciones de filosofía de la historia, confrontadas en las obras del americanista colombiano Germán Arciniegas (19001999):Con América nace la nueva historia y América en Europa. eran paliativos y no respuestas definitivas a una terrible verdad: el menguamiento racial que provocaba el trópico, comprobado por la inexistencia de civilizaciones a través de la historia en climas cálidos, y la existencia de estas solo en zonas templadas con variaciones estacionales(Villegas, 2005, p. 214).

Jiménez(1918) es enfático: la única posibilidad de regeneración, más allá de las medidas sanitarias que son remedio temporal, es mediante la inmigración nórdica, suiza, alemana del sur, belga y holandesa -todas de confesión protestante-, punto en el que coincidió con López de Mesa (1918) y en el que ambos se identifican con Friedrich Hegel (1770-1831) en su visión de América como continente ${ }^{3}$, al otorgar un peso especial a la geografía y a la incidencia del clima sobre el espíritu, idea bastante aceptada en ese momento por la importancia que este pensador tuvo a lo largo del siglo XIX en Europa y en América hasta bien corrido el XX, ya que su idealismo absoluto se constituyó, al lado del darwinismo social, como condición histórica para la configuración de la geopolítica en Alemania y demás potencias desde la lectura que hizo del Estado, la geografía y el territorio.

En opinión del prusiano y de naturalistas como Cornelius de Pauw (1739-1799)4 y Georges Louis Leclerc, conde de Buffon (1707-1788)

4 Se refería a América con palabras como estas: "No hay suceso más memorable entre los hombres que el descubrimiento de América. Remontándonos de los tiempos presentes a los más antiguos, no hay acontecimiento que pueda compararse con este. Y es sin duda espectáculo grande y terrible ver la mitad de este globo a tal punto desgraciado por la naturaleza, que todo allí es degenerado y monstruoso" (citado en Zea, 1978,s.p)

5 No menos diatriba expresa este autor para con el hombre americano, pues "aunque más ligero que el europeo, el salvaje del nuevo mundo es sin embargo menos fuerte de cuerpo; mucho menos sensible, más tímido y cobarde; no tiene ninguna vivacidad, ninguna actividad en el alma; la del cuerpo no es tanto un ejercicio, un movimiento voluntario, cuanto la urgencia de acción causada por la necesidad [...] Allá todo languidece, se corrompe, se sofoca. El aire y la tierra, cargados de vapores húmedos, dañinos, no pueden depurarse" (citado en Zea, 1978, p. 153-154). 
las zonas frías y tórridas no cuentan como escenario histórico universal, porque la conciencia despertada en ellas, es meramente natural y tanto el frío como el calor, le impiden al espíritu desarrollarse con plenitud. Por lo que "el auténtico escenario para la historia universal es, por tanto, la zona templada, y más en especial su parte septentrional, puesto que aquí la tierra tiene la configuración de continente y posee un amplio pecho" (Hegel, 1970, p. 104).

De esta forma, América es ubicada en el "nuevo" mundo, debido a su reciente "descubrimiento". Al entrar en contacto con el espíritu y guiada por él, ingresará a la civilización. Aunque su escepticismo es notorio con todo el continente, lo es menos con Norteamérica, pues le concede cierta ventaja al haber sido colonizada casi totalmente por occidentales protestantes, esto es, emprendedores y proclives a la industria. Por lo mismo, afirma que

América cae fuera del terreno donde, hasta ahora, ha tenido lugar la historia universal. Todo cuanto viene ocurriendo en ella no es más que un eco del viejo mundo y la expresión de una vitalidad ajena. En cuanto país del futuro, aquí no nos interesa; pues en el aspecto histórico, el objeto de nuestra atención nos viene dado por lo que ha sido y por lo que es. En filosofía, en cambio, no nos ocupamos ni de lo que ha sido ni tampoco de lo que será si no de lo que es y es eternamente: nos ocupamos de la razón, y con esto tenemos ya bastante que hacer(Hegel, 1970, p. 110).

En el extremo moderado del higienismo colombiano, se pensaba otra cosa: la raza no era degenerada por sí, sino que sus avatares se debían a condiciones económicas, sociales y políticas que había que subvertir a través de la educación, en opinión por ejemplo, de Jorge Bejarano (18881966), Lucas Caballero (1869-1942), Calixto Torres Umaña (1889-1960) y Simón Araujo, que atribuían a la pobreza, a la falta de higiene y a la pésima alimentación las causas de esa debilidad racial, (Villegas, 2005, p. 213-214).
Por su parte, López de Mesa (1929) en un punto medio poco definido, no habló de degeneración, sino de debilidad y depresión, entendidas en el escenario de los tres peligros más relevantes para Colombia:

Ahora sí señores, oíd mis conclusiones sintéticas: En este momento hay en Colombia, de un lado: I. Una soterrada amenaza estadounidense de restringir nuestra soberanía nacional; II. Una insuficiencia de educación que hace de nuestro pueblo un niño incapaz de luchar victoriosamente por la vida; III. Escasez de recursos económicos para el desarrollo general del país y en especial para la higiene de la porción enfermiza de nuestro territorio. Del otro lado, grupos étnicos vigorosos todavía, y con espíritu inteligente y alerta, que a través de un siglo de vicisitudes están a punto de sacar avante la raza y la República, (el antioqueño, principalmente) [...] (López de Mesa, 1920 p. 144, el entre paréntesis fuera del texto original).

Con independencia de las posturas extrema, moderada o ambigua de los higienistas en Colombia, lo que se puede inferir es que la medicalización de la raza y el modelamiento de los cuerpos a través de la legislación sobre la higiene, el alcoholismo, la educación y las enfermedades venéreas, fue una estrategia biopolítica indiscutible.

El capitalismo [...] socializó un primer objeto, que fue el cuerpo, en función de la fuerza laboral. El control de la sociedad sobre los individuos no se opera simplemente por la conciencia o por la ideología, sino que se ejerce en el cuerpo, con el cuerpo. Para la sociedad capitalista, antes que nada, lo importante era lo biológico, lo somático, lo corporal. El cuerpo es una realidad biopolítica; la medicina es una estrategia biopolítica (Foucault, 1992, p. 87).

Eran los médicos fungiendo como "legisladores" o asesores, los que definieron quién era el colombiano sano (virtuoso) y cómo había que tratarlo hasta bien entrada la pasada centuria, 
pues a través de esas estrategias biopolíticas (higienización y medicalización), la sociedad y el Estado daban respuesta desde la "ciencia" a las demandas que el entorno mundial y nacional les hacían en materia económica, principalmente. De ese modo, para Sáenz, Saldarriaga y Ospina (1997) los médicos e higienistas instauraron aquí la llamada moral biológica,

[...]que se oponía a la moral católica, y a partir de la cual los intelectuales considerados "modernos" pretendieron arrebatar a la iglesia, y a los intelectuales tradicionales, el control y el gobierno de la población. Esta nueva "moral biológica", fundamentada en saberes como la antropología, la criminología, la psicología experimental, la higiene y la medicina, concebía la acción del individuo como un resultado de factores, entre ellos, la herencia y el medio geográfico, restando importancia a la voluntad como suprema guía de la acción humana de acuerdo con la doctrina cristiana(Noguera, 2003, p. 210).

Cabe aludir a la rejilla de apropiación de ese tipo de pensamiento en este país, pues lo expresado, se enmarca en un amplio espectro, dentro de las ideas de Jean-Baptiste Lamarck (1744-1829), expresadas en 1809, como condición del darwinismo, el evolucionismo y de la biología que circularon y fueron absorbidas prácticamente en todas partes del mundo en el contexto del denominado "neolamarquismo".

En ese periodo, aunque no exclusivo en su recurrencia, se utilizó la tertulia -praxis común desde la colonia en la Nueva Granada- como espacio de encuentro y debate académico, esto es, de circulación y apropiación de ideas,y que forjó en torno suyo a toda una generación de intelectuales; unos, venidos de su periplo formativo o académico por Europa; otros, que se servían de él.

Así mismo, la Universidad Externado de Colombia fundada en 1886 como respuesta al dogmatismo regenerador católico y conservador, se convirtió en espacio para el flujo y asimilación de tales saberes, en el "pilar del liberalismo en la edu- cación superior y el seminario del pensamiento positivista spenceriano en Colombia"(Ocampo, 2007, p. 113).

El darwinismo social en Colombia data, más o menos, desde la segunda mitad del siglo XIX, periodo de la Revolución Industrial, de repudio a la metafísica y a la teología como instrumentos de comprensión de la naturaleza humana, de defensa de la ciencia y del racionalismo fundados en la experimentación. Es en ese clima de cierta "anarquía" intelectual, en el que irrumpe el positivismo, como discurso legitimador que buscaba restablecer el orden a través de reformas políticas o educativas, básicamente, aunque no las únicas. Y se dan, porque los lemas de la regeneración, a la que se deben, eran los binomios progresoevolución de los pueblos, barbarie-civilización, interés social-interés individual, libertad-orden.

Precisamente de tal entorno político e intelectual, en Colombia, buena parte de los pertenecientes a la Generación del Centenario, contraria al dogmatismo, procuró sacudirse, recurriendo a los saberes modernos imperantes(medicina y biología) en posturas como las ya presentadas $y$ en el racialismo ${ }^{6}$, doctrina atractiva para los simpatizantes del evolucionismo y su degeneración eugenésica.

El racialismo como ideología se caracteriza por dividir el mundo en razas (fuertes-débiles), equiparar raza con cultura (forma de dominación), la determinación del comportamiento individual respecto de la pertenencia a una cierta raza (se es más civilizado o más bárbaro dependiendo de ello), la utilización de una única escala jerárquica para valorar las razas (Occidente y su cultura son los patrones de la escala) y por la necesidad de actuar políticamente a partir del saber que se tenga sobre las razas (expansión, control, aislamiento, colonialismo, etc.).

Los saberes científicos fueron apropiados por los políticos e intelectuales de élite, atraídos como se dijo, por el neolamarquismo, con sus dos posturas relevantes para el tema del que se trata, esto es:

6 Cfr. el libro Nosotros y los otros. Reflexión sobre la diversidad humana de Tzvetan Todorov. 
1. La idea según la cual, las adaptaciones medioambientales se heredan; por tal razón, el ambiente moldea el carácter, la cultura y los fenotipos de los individuos, lo que da pie a que surja el interés por la puericultura, la familia, la educación, la pobreza y las enfermedades como especies de miserias raciales.

2. El higienismo vinculado con la eugenesia, entendió e impuso que el papel de la "ciencia", era el mejoramiento de las razas a través del conocimiento de las leyes de la herencia.

Con este acervo doctrinario e ideológico, era evidente que la debilidad racial del colombiano podía y debía intervenirse científica y estatalmente, produciendo civilización en el trópico, puesto que la acción humana es capaz de transformar el medio, mejor aún, los cuerpos, que son en definitiva, los que interesa medicalizar, como cláusula para propiciar la salud individual y colectiva, requisitos previos de la felicidad, el progreso y la civilización de la nación. La sanidad y la higiene son exigencias ineludibles para el Estado, independientemente de la ideología del gobierno de turno.

El industrial conservador antioqueño, Mariano Ospina Pérez (1871-1976), mandatario de Colombia entre 1946 y 1950, como presidente de la Federación Nacional de Cafeteros(el gremio económico más importante para la época),sostuvo (Villegas, 2005) que gobernar era ante todo sanear, incluso por encima de poblar, educar o "ferroviar"; porque el ejemplo lo habían dado históricamente las naciones más avanzadas, que sin ser las más ricas, sí fueron las más vigorosas.

Este tipo de ideas estaba tan extendido que Jorge Eliecer Gaitán, a quien se podría ubicar fácilmente en el polo opuesto del espectro político, manifestaba en 1937: "No habrá agricultura, no habrá industria próspera si persistimos en tener la raza débil que hoy tenemos; una raza tarda y lenta para el trabajo, que se fatiga a muy leve andar y que presenta los defectos psíquicos que todos conocemos, los que no son otra cosa que una consecuencia de los elementos biológicos y fisiológicos que les son característicos. Buscar gente inteligente y capaz; gente honrada y sociable en organismos débiles y enfermos, atacados de todas las taras atávicas herenciales y circunstanciales, es un imposible metafísico" (Villegas, 2005, p. 217).

A pesar de tal empeño, López de Mesa fue escéptico, aunque reconoció la fortaleza de la condición geográfica de Colombia: ancla entre centro y sur América por tener todos los climas y todos los cultivos, pero con el problema de la desintegración territorial y racial.

Si bien atrás se dijo que buena parte de los higienistas compartían la política de la inmigración como remedio eficaz contras las taras de la raza, el profesor admite el fracaso de la misma-no exclusivo de Colombia-, para lo cual, plantea como alternativa la estrategia eugenésica del poblamiento.

El fenómeno del poblamiento se cumple por imposición ineluctable, ora con loselementos adecuados, ya con los venidos a menos o ineficaces de suyo [sic]: Noquisimos nunca estudiar a fondo este problema, confiados en que las leyes del azar nos son propicias: $\mathrm{La}$ resultante es que donde pudiéramos tener ahora unos cuantos millones de ciudadanos de buen cruzamiento, asimilados y cultos $y$ tan patriotas como los descendientes de don Sebastián de Belalcázar, vemos ocupado el puesto por cepa más débil cada día, y por inmigradores [sic] de dudoso aprovechamiento racial y cultural(López de Mesa, 1970, p. 405).

El espacio propicio para este nuevo "experimento" fue la familia, institución que el Estado debía cuidar no solo con medidas educativas, sino desde la salud misma de los contrayentes. Será a través del cuidado del "genio" como finalmente se protegerá la raza, pues al fin y al cabo, él es el garante de su supervivencia.

Una selección que comprenda la contribución que a él deba aportar la familia, ensanchando un poco la procreación de los más aptos, y -a esta seudo-inmoralidad llegaremos muy 
pronto- limitando la reproducción de los desechos sociales que crece y crece ante el maltusianismo de los mejor dotados de una manera que conduciría fatalmente a una catástrofe de la especie humana, si no hubiera, como sí lo hay, un instinto social de previsión (López de Mesa, 1926b, p. 405).

Para lograrlo, propone la distribución del territorio colombiano atravesado por tres cordilleras: la central, la oriental y la occidental, acorde con una selección planificada de regiones privilegiadas, como: Boyacá (para colonizar los Llanos Orientales), Huila (para colonizar la Amazonía) y Antioquia. Este es tu terruño, el que como pocos puntos geográficos de Colombia, cumple casi a cabalidad con los fines eugenésicos del diserto profesor. "Parece raro que así lo diga, pero siendo ese Departamento el centro de la República geográficamente, y también como vigor de la raza, todo lo que sea robustecerla y depurar su sangre nos es útil" (López de Mesa, et al, 1920, p. 133).

Empero, y pese al protagonismo indudable que Antioquia tuvo y aún conserva en el proceso económico de Colombia, son muchos los mitos que rodean la constitución genética de su población, también presa de críticas y admiraciones, de diatriba y ditirambo.

El antioqueño era (y sigue siéndolo en términos generales) un "pueblo" conservador y católico que pese a eso, supo ubicarse y posicionarse política y económicamente en el contexto nacional marcado por el excesivo centralismo, gracias a su espíritu emprendedor y de habilidad para los negocios, sobre todo de explotación y comercialización del oro. Sus dirigentes tuvieron, según lo expresa el historiador Jorge Orlando Melo (1985), un pronunciado derrotero urbano y comercial que les permitió trabar con la iglesia relaciones más estratégicas y menos tensas como en el resto del país, donde esta tuvo un mayor control, pero que precisamente por ese hecho, despertó un anticlericalismo radical.

Cuando Colombia comenzó a girar hacia la centralización impuesta por la Constitución conservadora de Caro y Núñez en 1886, los pragmáticos dirigentes antioqueños catapultaron aún más a la región hacia un liderazgo indiscutible en materia económica, industrial, sanitaria y política que le ha valido hasta hoy, no pocos odios y amores. Esa era la raza que el "diserto" profesor admiraba y a la que veía con la suficiente capacidad para sacar al resto de la nación adelante, pero cayó en el juego atractivo del centralismo y fue presa de esa máquina.

\section{B. Lectura política y jurídica del biologicismo desde Luis López de Mesa}

El biologicismo determinista que, entre otros, prohijó Luis López de Mesa, a pesar del cuestionamiento del que fue objeto por su espíritu "racista", se constituyó en condición de posibilidad de leyes $y$ de reformas en materia educativa, sanitaria, laboral, penal y constitucional. Esa particular forma de ver el mundo, quiso, en cabeza de sus defensores, resolver a través de las relaciones políticas (en las esferas y niveles del Estado y del gobierno), científicas (en las academias científicas y universidades), sociales (en organizaciones de todo tipo, como la iglesia) y jurídicas (en las facultades de derecho y el Congreso), buena parte de los problemas de la sociedad colombiana a la altura de la década de los años treinta del siglo $\mathrm{XX}$ conla población representada ya como raza y no tanto como pueblo.

Sin embargo, esa intención se truncó en $1948^{7}$ porque las minorías selectas, social y racialmente, no fueron capaces de llevar a cabo la misión,

Ese año, en concreto el 9 de abril, cuando apenas empezaba la tarde y en plenas deliberaciones de la IX Conferencia Panamericana -centrada en atacar el comunismo en América Latina-y su conferencia alterna, la de los estudiantes latinoamericanos liderada por el joven Fidel Castro -centrada en defenderlo-, fue asesinado en Bogotá el abogado penalista (discípulo aventajado de Enrico Ferri), exparlamentario, exministro de Educación y caudillo liberal, Jorge Eliécer Gaitán Ayala (1903-1948), considerado por muchos, como el más posible ganador de la candidatura presidencial por el Partido Liberal. Tal hecho conmovió a todo el país, pues "El Bogotazo" como se conoce históricamente lo sucedido ese día, originó una ola de violencia en las calles que fue casi imposible de controlar y que se sumó a la larga cadena de violencia política por la 
como lo reconoce el propio López de Mesa en sus libros Escrutinio sociológico, Los problemas de la raza en Colombia, Posibles nuevos rumbos de la economía colombiana y Nosotros. Se puede decir que tanto él como su generación, fue "optimista sobre Colombia en 1920, ya pesimista en 1944 y casi nihilista en el fondo de su ser después de 1948"(Uribe, 2007, p. 378) Eso fue a su pesar, retórica higienista, termina reconociendo. Y esta a su vez, será una de las condiciones históricas para el intervencionismo estatal en el primer periodo presidencial del liberal Alfonso López Pumarejo entre 1934 y 1938, denominado la "Revolución en Marcha" por su espíritu reformador y de cambio ${ }^{8}$. Es precisamente en ese intersticio, ejerciendo los cargos de ministro de Educación en 1934 y de canciller en 1938-ya en la administración de su amigo Eduardo Santos-, donde López de Mesa hizo significativos aportes en propuestas de reformas de diverso orden normativo, que buscaban poner en sintonía a Colombia con el mundo 9 y organizar internamente los dispositivos para "gobernar" a la población.

Para el efecto, se utilizaron estrategias biopolíticas: (i)la creación de la Radiodifusora Nacional

que ha pasado este país desde su conquista, colonia e independencia. Con este "magnicidio", Colombia siguió transitando por senderos oscuros cargados de violencia en los campos y en las ciudades, protagonizada por los simpatizantes de los dos partidos políticos tradicionales: Liberal y Conservador, que atribuían cada uno y a su manera a sus contradictores la muerte del líder popular. Ahora bien, hay otros que opinan que fue gracias a este acontecimiento y lo que significó, que aparecieron los primeros grupos alzados en armas en la década de los sesenta (las Fuerzas Armadas Revolucionarias de Colombia, Farc, en 1964 y el Ejército de Liberación Nacional, ELN, en 1966).

8 Este periodo presidencial, al igual que los demás comprendidos entre 1930 y 1946, forma parte de la llamada "República Liberal" que buscaba diferenciar claramente a los gobiernos liberales de los que le precedieron en la llamada "Hegemonía Conservadora".

9 Por ejemplo, López de Mesa en su discurso como canciller de Colombia ante la VIII Conferencia Panamericana en Lima en 1938, propuso la creación de la Liga de las Naciones Americanas, antesala de lo que la IX Conferencia Panamericana de Bogotá en 1948 convertirá en la Organización de Estados Americanos (OEA). de Colombia en $1940^{10}$-siendo ministro de Educación Jorge Eliécer Gaitán-,con el fin de "ilustrar" al pueblo, culturizarlo a través de un medio masivo de comunicación como la radio, principalmente dirigido a los campesinos analfabetas; y (ii)el Programa de Cultura Aldeana, inspirado en el modelo británico de la campiña y pregonado por López de Mesa desde 1920 en sus conferencias sobre la raza, en las que recomendaba a cada pueblo tener como mínimo un médico, un dentista, un inspector escolar, un abogado de pobres, un arquitecto urbanista, un pedagogo y un sociólogo ${ }^{11}$.

El Estado colombiano en 1940 bajo el mandato presidencial de Eduardo Santos y, en el que las ideas de López de Mesa se aplicaron directamente, tenía bastante claro el papel de la educación como factor de cohesión social a través de la cultura (utilizó las escuelas ambulantes, las instituciones, los museos, el cine, la radio y el libro), porque, al fin $y$ al cabo,

[...]hacer vivir a las demás secciones del país el mismo ritmo vital de cada uno de los departamentos, tiene como fin esencial el ir creando una consciencia unánime de la

10 El poder y posibilidades de la radio son advertidos por el escritor alemán Bertolt Brecht (1898-1956) en su teoría sobre este medio masivo de comunicación, al sostener que "La radio podría ser el más gigantesco medio de comunicación imaginable en la vida pública, un inmenso sistema de canalización. Lo será cuando no sea solo capaz de emitir, sino también de recibir. En otras palabras, si consigue que el oyente no solo escuchase sino también hablase, que no permaneciera aislado, sino relacionado". Disponible en http://bibliotecavirtual.clacso.org.ar/ar/libros/colombia/assets/own/ analisis\%20politico\%2041.pdf

Para el caso de la Radiodifusora Nacional de Colombia, véase el estudio del destacado investigador de la Universidad del Valle Renán Silva, que tiene por título: Ondas nacionales. La política cultural de la República Liberal y la Radiodifusora Nacional de Colombia.

11 Cfr. una referencia más detallada sobre este proyecto, en el capítulo de Carlos Uribe sobre López de Mesa (pp. 378-380) de la obra colectiva Pensamiento colombiano del siglo XX, publicada por la Pontificia Universidad Javeriana y su Instituto Pensar en el 2007 y coeditada por Santiago Castro-Gómezy Guillermo Hoyos Vásquez, entre otros. 
nacionalidad colombiana, a la par que una compenetración viva de ideas, sentimientos y emociones, modelos perdurables de la cultura(Ministerio de Educación Nacional, 1940).

Se pasa ahora a una sucinta referenciación de los aportes del biologicismo determinista y de López de Mesa en asuntos de contenido normativo en materia educativa, sanitaria y penal; aunque sin desconocer las propuestas del profesor en materia laboral como la implementación del salario mínimo para los trabajadores y la igualdad de derechos para la mujer en el orden constitucional, que posteriormente se aplicaron en Colombia, así las razones para ello hayan sido más de tinte económico y político.

\section{Materia educativa}

Como ya se mencionó, el proyecto educativo que López de Mesa planteó para los colombianos, es central en su pensamiento. Fue a través de la estrategia educativa, siguiendo en todo, los cánones de la biopolítica -que posibilita y conduce a la disciplinarización de los cuerpos, o lo que viene siendo lo mismo, de los sujetos-, como se quiso dar forma a la pretensión higienista de modernizar la sociedad, preparándola intelectual, física y moralmente para afrontar los retos de su desarrollo en el marco de una economía mundial que ya no era igual a esa altura de la centuria. Para lograrlo, se da el tránsito de una moral católica a una moral biológica que acarreó bastantes enfrentamientos ideológicos entre el Estado y la iglesia, lo que se evidenció con la reforma educativa de 1936 mediante la cual, la iglesia fue despojada de la función educativa, ejercida hasta entonces y desde la implantación de la hegemonía conservadora.

A ese respecto, los autores de la obra Mirar la infancia(1997), Sáenz et al., clásica en la investigación de ese periodo, sostienen que en Colombia en los primeros treinta años del siglo $\mathrm{XX}$, se hicieron visibles por lo menos cuatro debates importantes sobre la naturaleza humana, las características de la infancia, las disputas iglesia-Estado y los proyectos de reforma na- cional en la que el otrora protagonismo de la pedagogía (en ese momento, entiéndase de los maestros), sucumbió principalmente gracias a dos factores: las preocupaciones de índole económica que la comenzaron a condicionar y las disputas partidistas.

No estuvieron ausentes las paradojas, pues como lo anotan los investigadores, el Estado, los intelectuales y las instituciones de saber pedagógico quisieron conciliar las contradicciones evidentes entre opuestos que tocaban con el orden social, la autonomía, la libertad, las creencias católicas, el pragmatismo, el determinismo biológico, lo antiguo, lo moderno, el castigo, el control social, la democracia, el conocimiento científico, la militancia partidista y las oportunidades sociales para la mujer, entre otras.

Así las cosas, se puede historiar lo moderno en la educación y en la pedagogía, con base en un tejido construido por lo educativo, lo pedagógico, lo político y lo religioso. En ello, lo moderno por sí solo no reordenaba nada, ya que requería de todo un proceso de apropiación, que se puede visualizar por fases, a saber:

1. Lo moderno en Colombia está atravesado por la biología y las teorías evolucionistas, extendiéndose a:

- La sociedad entendida como organismo en la que cada miembro (individuo) tiene una función específica.

- Los individuos se seleccionan a través de instrumentos técnicos de carácter médico y psicológico (test, examen, la observación, la mirada).

Esto se mantuvo hasta mediados de los años treinta del siglo anterior, puesto que el interés era remediar los problemas biológicos de la raza degenerada que urgía de medidas curativas de orden moral y social. Todavía no había ocurrido la separación entre lo laico y lo religioso, entre otras razones, porque la hegemonía conservadora todavía no había finalizado, siendo claro para el Estado, controlar las iniciativas privadas, las instituciones y los mecanismos de modernización, 
básicamente mediante la manipulación de lo religioso.

Tal estrategia se hizo evidente a partir de la ley 39/1903, encargada de comenzar a canalizar lo moderno acorde con la tesis de que lo religioso no importa si el engranaje es civil. De este modo, lo estatal y lo eclesiástico, propiciaron la escisión entre lo técnico y lo filosófico (modernización-modernidad).Así, la modernización social, imponía a la pedagogía:

- Abandonar las cuestiones tradicionales.

- Acogerla comprensión de la adaptación biológica como condición de la evolución.

- Formar un individuo activo y productivo según las necesidades sociales.

- Exigir a los intelectuales desdeñar de lo tradicional por hallarse fuera del alcance científico.

En esencia, lo que se pretendió en ese periodo, era mostrar el funcionamiento de la apropiación del saber pedagógico, asumiendo por apropiar, el acto de inscribir cualquier saber o producción originados en una determinada sociedad y sus condiciones históricas, en la realidad particular de otra, afirman los autores del texto referenciado.

2. Problemas de modernización de la escuela primaria entre 1903 y 1930:

Desde que se implantó la escuela pública primaria en el Nuevo Reino de Granada a finales del siglo XVIII, ya se tenían rasgos de modernidad como el uso del tiempo, la disciplina, la división del trabajo y la homogeneización e individualización de sujetos y saberes, según lo mostró el profesor de la Universidad del Valle en Colombia, Alberto Martínez Boom (1986) en su libro Escuela, maestro y métodos en Colombia 1750-1820.

La preocupación fundamental del ideal de modernización se centraba en los locales de las escuelas. La insistencia de los creyentes en la escuela activa, era que concebían el aula de clase como un laboratorio abierto al mundo, empezando por su apariencia física y regentada por médicos y maestros. Solo hasta 1924 puede hablarse de la modernización de la instrucción pública. En tal dinámica, el clasificar a los niños según sus capacidades, era vital.

El acto fundador de una escuela era la clasificación de los alumnos por el maestro: se efectuaba el primer día de clase, 'día sagrado', al cual dedicaban los manuales un capítulo especial, pues en él se iban a grabar en el niño las impresiones que favorecerían el éxito o el fracaso de su escolarización. El ritual de entrada se componía de un saludo paternal; la colocación de los alumnos en orden, obedeciendo a las señales de la táctica escolar, y, luego, la toma de lista y la recitación de la oración(Sáenz et al., 1997, p. 285).

Con esta práctica, la autoridad paterna quedaba desplazada, porque al fortalecer y elevar por encima suyo, a la figura del maestro, era el Estado mismo quien ocuparía el primer peldaño en la jerarquía social. Algo percibido fácilmente al privilegiarse lo que el niño aprendía en detrimento de lo que pudiese poseer de acuerdo con su edad. El fin era claro: nivelar a cada estudiante, establecer el sistema de tareas como estímulo a los "buenos" y castigo a los "malos" e impersonalizar la jerarquía en la escala del aprendizaje.

La modernización de la escuela colombiana se completará con la utilización del cuaderno y los asientos unipersonales. Esa estrategia educativa, mediada por las leyes que se expidieron, quiso formar un colombiano regenerado, esto es, moderno, tal y como se necesitaba para ese momento histórico debido a las exigencias que el mundo productivo le iba colocando a la economía nacional; es ahí precisamente en donde las estrategias biopolíticas seguían siendo útiles a los propósitos políticos y sociales.

Por ejemplo, el "diserto" profesor en un discurso pronunciado ante obreros en 1910, al preguntarles qué le iban a enseñar a sus hijos, tras una larga alusión a ideas y personajes que en su vida seguramente nunca habían escuchado, les decía en un tono convincente: 
iObreros! Les vais a enseñar dos cosas: un oficio para que se ganen honradamente el pan, y una cultura general para que se ganen conscientemente la estimación de sí mismos.

Ese oficio será el vuestro, si vuestro hijo no tiene disposiciones excepcionales para otro, por razones capitalísimas: porque la herencia, por sus leyes misteriosas, le hará a él más fácil el trabajo en que os habéis formado vosotros, y porque en vuestra casa y en vuestro taller encontrará listo ya y seleccionado todo lo que necesita para su aprendizaje.

Solo que si os es fácil transmitir a vuestro hijo el oficio que profesáis, no lo es tanto ni con mucho, darle una cultura general. Esta es muy exigente. Necesitáis inculcarle estas tres cosas fundamentales: un respeto razonado de sí mismo, un respeto razonado de los demás, y alguna instrucción.

El respeto de sí mismo se refiere al cuerpo y al espíritu. Por parte del cuerpo, deberá ser fuerte y pulcro. El respeto a los demás significa que debe ser justo, sin soberbia ni humildad; sin egoísmo ni servilismo; respetable y respetuoso.

Con relación a la instrucción, debéis dotarlo según sus capacidades [...]

No es la instrucción, sin embargo, el ideal de la educación moderna: es la cultura, es la preparación del cuerpo y del espíritu para una vida sana y noble.

Y la educación del niño requiere condiciones excepcionales, que exigen del profesor y del padre una vocación preparada(citado en Carranza y Barrientos, 1981, pp. 30-31).

La preocupación por el cuidado y educación de los niños inaugurará un paradigma basado en la primera infancia como política pública de primer orden aún hoy.Allí la familia se redefinió como el espacio para introyectar una nueva actitud frente a la salud y su cuidado, por eso las medidas profilácticas cobrarán todo su vigor.

\section{Materia sanitaria}

En la tercera parte del documento que da cuenta de los resultados de una investigación sobre el Proceso de institucionalización de la higiene: Estado, salubridad e higienismo en Colombia en la primera mitad del siglo XX, María Teresa Gutiérrez, (2010) analiza cómo la ley 96/1938 que creó el Ministerio de Trabajo, Higiene y Provisión Social, tenía como objetivo básico lograr que todas las entidades públicas y privadas, contribuyeran económicamente a la realización de campañas de higiene, formando un fondo común para el sostenimiento de los servicios; empero, los departamentos de Colombia (así se divide político-administrativamente el país) con excepción del pragmático Antioquia (el natal de López de Mesa), vieron limitada su autonomía $y$ se resistieron a esta estrategia.

Aquí en cambio, se creó la Secretaría Departamental de Higiene y Asistencia Social dependiente del gobierno central. Con esa decisión, a partir de 1937, el trabajador en Colombia será visto por el Estado como un productor de riqueza y su salud, un asunto de responsabilidad patronal.

Dos años más tarde, en la X Conferencia Panamericana Sanitaria en Bogotá, antecedida de la realizada en Buenos Aires y presidida por la nueva estrella del higienismo nacional, el médico Jorge Bejarano, el ministro de Trabajo Alberto Jaramillo Sánchez en su instalación, expuso la necesidad de explicar la relación entre el trópico y las enfermedades como las causantes de la debilidad del pueblo, ya no raza, por medio, valga decir, de campañas antivenéreas y antituberculosas, pues quienes las contraían y transmitían, eran personas de dudoso comportamiento moral y social a las cuales había que vigilar, controlar y educar.

Difícil conseguir el ideal sanitario en climas como los nuestros, pero para buscarlo no han de faltar a este gobierno ni entusiasmo ni constancia en el esfuerzo; porque sabe que al perseguirlo defiende y acrecienta el único capital invaluable de que disfrutan las naciones: el hombre, como núcleo permanente 
de la raza, como proyección, seguirá hacia el porvenir (Jaramillo, citado en Gutiérrez, 2010, p. 93).

Por lo mismo, propondrá la formalización del oficio de higienista caracterizado por el sacrificio, la dedicación de tiempo completo y la desvinculación profesional a que ello obligaba, formándolo como técnico, preferentemente en el exterior y en países mejor "dotados" que Colombia. Eso se concretó con la ley 100/1928.

La creación del Ministerio de Trabajo buscaba la tecnificación de la administración de los asuntos sociales como condición previa para la posterior creación del Ministerio de Higiene, aunque ese proyecto tuvo la dificultad de que en la década de los años cuarenta del siglo XX, se insistió en la idea de apartarlos asuntos de higiene (con fundamento técnico) de los asuntos laborales (de fundamento político).

Por eso la ley 27/1947 creó el Ministerio de Higiene separando las materias de higiene y asistencia pública de las laborales y de seguridad social que se reservaron al Ministerio de Trabajo. Tal normatividad se inspiró en las investigaciones de los higienistas asesores del gobierno conservador del ingeniero Mariano Ospina Pérez.

Con la higiene como responsabilidad estatal, los higienistas-médicos e ingenieros sanitarios- se convirtieron en una élite tecnocrática que pretendía mejorar las condiciones del pueblo con la adopción de políticas públicas que se soportaban en teorías racialistas, que si bien tenían un carácter ideológico, fungían de científicas para la época al ser presentadas como necesarias para el país.

\section{La ley 29/1922 consagró que}

[...]los establecimientos de beneficencia o asistencia pública que fueran costeados por el tesoro nacional, departamental o municipal debían someterse a las ordenanzas de la institución higiénica correspondiente; es decir, debían comprobar sus reglamentos con el director nacional de Higiene, con el director departamental o con el médico municipal, según fuera el caso.

Para el año de 1925 se expidió la ley 15, en la cual se estipulaba que la asistencia pública estaría encargada de las campañas contra las enfermedades venéreas y la tuberculosis, como también de la protección de la infancia. La mortalidad infantil y la tuberculosis empezaban a aparecer insistentemente como problemas de salubridad pública, junto con las enfermedades venéreas y el alcoholismo, las cuales eran caracterizadas como enfermedades sociales puesto que se extendían y propagaban, amenazando a la sociedad y su futuro. Por esta misma ley se le cambió el nombre a la Dirección Nacional de Higiene, incluyéndosele la asistencia pública y asegurando de esta manera un control estatal sobre las instituciones de beneficencia que realizaban este servicio. Dicho cambio significó también la transformación de la manera en la que hasta el momento se venía administrando la institución higiénica en el país(Gutiérrez, 2010, pp. 85-86).

Sin embargo, el evidente fracaso de la propuesta inmigratoria del ala radical del higienismo colombiano en ese periodo, hizo enfocar la atención en la infancia como la esperanza de la regeneración mediante la educación, como ya se dijo atrás.

En esa dirección, ya desde 1916, en una línea más cercana a López de Mesa que a los higienistas radicales, en el informe expuesto por el director departamental de Higiene del departamento de Antioquia, Juan B. Londoño, se denunciaba la excesiva mortalidad infantil atribuida a causas que se habían podido impedir si se hubiesen tomado medidas higiénicas drásticas. Decía:

Los medios de evitar la excesiva mortalidad infantil son múltiples, pero desgraciadamente de difícil aplicación. ¿Cómo impedir, por ejemplo, los matrimonios consanguíneos y entre individuos en grado avanzado de degeneración, o de avanzada edad o sifilíticos, para que los niños no nazcan plenos de taras 
y sin resistencia vital? (Londoño, citado en Gutiérrez, 2010, p. 87).

A pesar de estas quejas, el servicio de protección de la infancia solo se organizó a finales de 1929 como una parte importante de la asistencia social. Este servicio tenía dos objetivos: los niños enfermos y los niños sanos, a los cuales se les brindaba alimentación y cuidados en las denominadas gotas de leche. Además, se les hacía un seguimiento en su desarrollo, y los niños enfermo serán atendidos en las distintas instituciones caritativas del país (Quevedo et al., 2004, p. 244. Citado en Gutiérrez, 2010, p. 87).

El investigador Santiago Castro-Gómez del Instituto Pensar de la Pontificia Universidad Javeriana (Bogotá), conceptúa a partir de una investigación titulada "Capitalismo y biopolítica en Colombia (1900-1934)"que ciertamente la inmigración no fue la solución al problema de la raza; que la población no era ingobernable por ser degenerada racialmente; al contrario, se podía gobernar a través de la biopolítica y sus estrategias para fortalecerla. En ello se detiene en la postura que defiende en su momento López de Mesa en el sentido de no insistir más en la inmigración, sino en la educación, porque como lo dijera el también médico Laurentino Muñoz:

No es que el colombiano sea étnicamente inferior, ni que el trópico inhiba la mente o consuma la energía: la influencia del sol ardiente no es causa de decadencia orgánica, pero sí lo son las enfermedades, los vicios, las condiciones antihigiénicas del suelo, la nutrición defectuosa o insuficiente. Un pueblo bloqueado por el paludismo, anemia tropical, pian, sífilis, blenorragia, tuberculosis, alcoholismo, intemperante y abandonado sentido común, no es precisamente promesa ni pequeña ni extraordinaria (citado en Castro-Gómez, 2007, p. 52).

El problema no será biológico sino social y político; por lo mismo, compete al Estado y solo a él, remediarlo. Lo que ocurrió fue que con la sola intención de instaurar el modelo civilizatorio y sus promesas de progreso, desarrollo, libertad e igualdad, se pudo hacer muy poco realmente. Por ello, se llamó la atención a los médicos para que ejercieran como "salvadores" de la vida, sus "reconquistadores"; era convertir ni más ni menos la medicina en ciencia política (Noguera, 2003).

Queda claro que el problema es la vida pero como acción creativa sobre la naturaleza, básicamente a través del trabajo productivo como conditio sine qua non para alcanzar el fortalecimiento y consolidación de la clase obrera colombiana. Así, ser improductivo será un asunto de inmoralidad. Liberarse económicamente, será liberarse espiritualmente. Esa fue la apuesta del Estado: vivificar a la población para que produjera, o como propuso Condorcet (1743-1794), el ilustrado francés, si la revolución conquistó la libertad para el hombre, la educación sería el instrumento para formar su carácter proclive a la obediencia, porque un hombre obediente produce y,si produce, renta; si renta debe tributar al Estado y así, este se hace rico y solo un Estado rico es poderoso.

Si se robustece al Estado para convertirlo en una máquina productora, podrá este a su vez, forjar sujetos modernos, no al estilo del ciudadano ilustrado que sabe porqué piensa, habla y actúa; sino para la producción y el consumo, el requerido para la industrialización de Colombia. Con ese norte, los gobiernos liberales emprendieron cualquier cantidad de reformas para lograr ese propósito "nacional".

En eso, el mentado Laurentino Muñoz sostuvo que

[...]si contara el país con generaciones trabajadoras, de carácter, con la independencia del esfuerzo personal, si la masa, el tipo medio de la juventud tuviera un concepto claro y definido del trabajo, entonces nuestra nacionalidad sería un derrotero de la civilización, una esperanza de la especie, o al menos un grupo étnico en capacidad de lucha, de animación (citado en Castro-Gómez, 2007, p. 53). 
Max Weber (1864-1920) en 1905 planteó que entre las creencias y el mundo económico-social hay una indudable interdependencia, tesis defendida por los calvinistas y sustentada en la teoría de la predestinación divina, consistente en que los hombres que trabajan, ahorran y acumulan garantizarán sin lugar a dudas su salvación; ya que si se hace lo contrario, lo que se obtendría será seguramente la condenación.

Si la vida es una lucha diaria y sin certezas, si la predestinación se alcanza por los frutos de la vida, si el trabajo es un sacramento por ser consecuencia normal de la vida interior del hombre, si el préstamo con interéses el anticipo sobre la producción, es decir, es la participación anticipada del acreedor en las ganancias del deudor; por todo eso, es inmoral y, por ende, ofensivo con Dios dar limosna a otros, porque la miseria es el castigo por la pereza. De por sí, ser pobre es ser inmoral y querer seguir siéndolo es doblemente inmoral.

En ese contexto, la familia será un mecanismo de unificación y cohesión social imprescindible, como también lo defendió López de Mesa. En una tesis para optar al título de doctor en Derecho y Ciencias Políticas que data de 1922, referenciada por Castro-Gómez (1922), su autor, con ideas más morales que jurídicas, propuso el tema de la disolución de la familia en Colombia, causada entre otras cosas, por la tendencia a la vida en unión libre y a las relaciones sexuales prematrimoniales que terminaban finalmente afectando los intereses económicos de la nación.

Apoyado en la autoridad de Malthus, nuestro flamante candidato al doctorado recomienda la creación de un estatuto jurídico que favorezca los matrimonios tardíos y castigue la promiscuidad sexual con el fin de promover la selección de los más aptos para trabajar. La prohibición estatal del matrimonio antes de los veinte años y el castigo ejemplar de las relaciones extramatrimoniales después de esa edad permitiría que los obreros no se casaran tan jóvenes y concentraran sus mejores fuerzas vitales en la producción de riquezas, aun después de consumado el matrimonio(Videla citado en Castro-Gómez, 2007, p. 53).

Por ende, es tarea del Estado preparar las condiciones sanitarias para la reproducción de los futuros obreros, incluso antes de su nacimiento. Posibilitar, a través de dispositivos normativos como instrumentos biopolíticos, que la naturaleza haga su propio trabajo de selección natural.

Los barrios obreros y las escuelas fueron entonces diseñados por médicos, ingenieros sanitarios y urbanistas como máquinas higiénicas. Se pensaba que el obrero encontraría en la nueva habitación higiénica del barrio obrero, el verdadero hogar que lo alejaría por fin de la taberna, del vicio, del alcohol; todo ello, propiciado por el nuevo papel que le fue encomendado a la mujer de los sectores populares: convertirse en madre $y$ esposa, y transformar su vivienda miserable y antihigiénica en un hogar (Noguera, 2003, p. 211).

\section{Materia penal}

Lo ocurrido en Colombia en esa primera parte del siglo XX en materia penal bien puede analizarse con los planteamientos de Michel Foucault (1926-1984), cuando sostuvo, por ejemplo, que la modernidad con su nueva concepción de la economía y de los sujetos a partir de la Revolución Industrial, hizo cambiar también la idea que se tenía del conocimiento.

Este es ya una conquista; es el resultado de la pugna constante entre saber y poder, en donde emerge de ciertas prácticas sociales, la verdad; es un asunto estratégico. Así, le interesaba mostrar cómo esa pugna produce un determinado tipo de subjetividad al igual que un discurso válido (dominio de saber, en este caso, el jurídico-penal) que se impone a esa subjetividad (régimen de verdad) (García, 2006).

Por eso historiar el contexto social de lo jurídico, implica atender a la relación entre verdad, biopolítica y derecho. Allí se da la verdad del discurso 
jurídico que sienta las bases para la intelección de la justicia, la moralidad, la eficacia, la positividad y la validez de tal discurso, entre otras cosas.

En su Genealogía del racismo, el filósofo francés construye su postura con estos tres conceptos, "mi problema es establecer qué reglas de derecho hacen funcionar las relaciones de poder para producir discursos de verdad" (Foucault, 1992, p. 34). Quiere escudriñar los dispositivos mediante los cuales se hacen visibles las relaciones del hombre con la verdad y, para conseguirlo, es indudable hurgar por su dimensión política.

Al ser la contemporánea, una sociedad disciplinada, ella misma establece unas especiales relaciones de poder y de prácticas penales con sus respectivas formas de saber, tipos de conocimiento y de sujetos de conocimiento que emergen e interactúan colectivamente.

Ya ni el delito es una falta moral, ni el delincuente un pecador. Ellos se emparentan con la afrenta a los valores apreciados por la sociedad. Por tanto,

[...]el crimen y la ruptura del pacto social son nociones idénticas, por lo que bien puede deducirse que el criminal es considerado un enemigo interno. La idea del criminal como enemigo interno, como aquel individuo que rompe el pacto que teóricamente había establecido con la sociedad es una definición nueva y capital en la historia de la teoría del crimen y la penalidad (Foucault, 2011, p. 40).

El derecho penal de ser un instrumento de protección social pasa a convertirse, verbigracia, los postulados panópticos de Jeremy Bentham (1748-1832), en una preocupación constante por el individuo, puesto que los jueces y los jurados, en especial consideración con el sujeto que juzgan, lo discriminarán, atenuándole o agravándole su conducta. Con este régimen de verdad, que mitiga o agrava, los intereses sociales se diluyen cada vez más, pues el carácter universal, impersonal y abstracto de la ley queda en entredicho (García, 2006).
Por ende, el panoptismo, como la disposición a la vigilancia que cada quien ejerce sobre el otro en una sociedad disciplinada, arremete contra el principio de legalidad defendido por Cesare Beccaria (1738-1794),en el sentido de que cuando se ejerce tal vigilancia con miras a controlar y seleccionar a unos individuos como deseables y a otros como lo contrario, se imponen los prejuicios morales; ya la lógica hace creer en lo que ese sujeto escogido socialmente a través de ciertos patrones pueda hacer, mas no, en lo que efectivamente haga.

Esa tensión entre derecho y moral, visibilizada en la pugna entre el legalismo del italiano y el panoptismo del inglés, se constituyó a su vez, en posibilidad para el surgimiento del peligrosismo penal en el que en definitiva la moral, fundada en el acervo genético y en la apariencia física de los individuos, determinará con criterios biológicos a los sujetos a delinquir inexorablemente. Se tiene pues que panoptismo y peligrosismo van de la mano.

La postura legalista queda desfigurada. Por eso, el panoptismo será un nuevo tipo de saber, de vigilancia y clasificación de los individuos y de estos entre sí sobre la base moralista. Algo que en la Colombia de la primera parte del siglo XX tuvo un protagonismo especial desde los postulados biologicistas con los cuales los médicos como políticos, asesores, funcionarios estatales o legisladores, no solo clasificaron o ayudaron a clasificar a la población entre: rico-pobre, sano-enfermo, negro-blanco, incapaz-capaz, retrasado-inteligente, inmoral-virtuoso, degenerado-civilizado, ateo-creyente, entre otros, sino que la medicalizaron y la higienizaron.

Así se refiere el investigador Carlos Ernesto Noguera en la obra Medicina y política, cuando afirma que "se trata de un problema [...] cuya expresión histórica puede plantearse en los términos de un doble proceso de medicalización de la política y politización de la medicina"(2003, p. 41).

Lo destacable no es tanto si los médicos se tomaron el poder o si los políticos se aliaron 
con los médicos, como observar la articulación y funcionamiento entre esos dos saberes: el médico, más concretamente, el biológico, y el político para delinear las estrategias biopolíticas ${ }^{12}$ que buscaban formar en la población, ciertos hábitos exigidos socialmente y para los cuales, el derecho penal fue un particular contribuyente.

En el contexto económico, político y social colombiano a partir de lo dicho hasta esta parte, se requería entonces de un nuevo tipo de mestizo acorde con las necesidades de la República; es ahí en donde la eugenesia como método cobra su importancia, aunque no en exclusiva en las leyes educativas o penales, sino también en otras como las del control de la familia que enfatizaron en la vigilancia y el cultivo de la educación y de la salud de los cónyuges.

Por su parte, las referidas a la delincuencia, básicamente a los pobres, en las que el derecho preventivo que enfatiza en la personalidad del autor y no sobre el acto, redundó en el control y la defensa como instinto social, ideas plasmadas en el Código Penal colombiano de 1936 en el que postulados de la Escuela Positivista del italiano Enrico Ferri (1856-1929)- como que el delito es un hecho natural y sociológico cimentado en el biopsiquismo del delincuente-, fueron apropiados acríticamente.

Tales ideas tienen como condición histórica y epistemológica el peligrosismo de Lombroso (1835-1909) y el positivismo criminal de Garofalo(1851-1934), a su vez condicionados por el darwinismo de Spencer y la teoría de la degeneración de Bénédict Morel (1809-1873), esta última bastante difundida en Colombia al iniciar y mediar el siglo anterior y que grosso modo, atribuye al alcohol y a las drogas la causa de las enfermedades mentales y a estas, la delincuencia;

12 "Habría que hablar de 'biopolítica' para designar lo que hace entrar a la vida y sus mecanismos en el dominio de los cálculos explícitos y convierte al poder-saber en un agente de transformación de la vida humana" (Foucault, 1989, p. 173)

13 Consúltese en http://www.emiliomartinez.net/pdf/ Aporofobia.pdf por lo que todo delincuente es un degenerado $y$ todo degenerado es un delincuente, en acto o en potencia.

Para el sociólogo del derecho, Germán Silva García (2009) en Colombia, aunque expandido en toda Latinoamérica, el positivismo criminológico tuvo un acento biológico y antropomédico. Considera que el concepto de degeneración es genealógicamente criminológico. Véase que en Italia se asimilaba la criminalidad con la desviación sexual, la locura, el pauperismo y la mendicidad. Como lo dijera el ítalo-argentino José Ingenieros (1877-1925), ese imaginario circula no solo en la mentalidad colectiva, sino que se consagra en los tipos penales.

Y la manera de hacer producir y hacer circular ese imaginario aporofóbico ${ }^{13}$ y de criminalidad, es a través, piensa Silva (2009), de los genéricamente llamados publicistas: periodistas, columnistas, políticos, presidentes, ministros y críticos de arte. Todos, realizan un ejercicio subjetivo que denota ciertas creencias expresadas en un lenguaje cargado de definiciones $e$ interpretaciones de descalificación moral, primero, y social y jurídica, después; al fin y al cabo, los tipos penales, son un juicio de valor negativo sobre una determinada conducta declarada previamente por el colectivo como dañina para sus intereses.

En ese escenario publicitario, aquí, al mestizaje se le llamó "combustión racial", que logra su cénit en los códigos Penal de 1936 y de Procedimiento Penal de 1938; ambos, generaron prácticas judiciales que querían combatir la tendencia o predisposición al crimen (pecado mortal) utilizando estrategias de prevención, defensa y control social (ascesis o profilaxis), que terminaron inventando la criminalidad y haciéndola realidad. Y para ese fin, fueron particularmente útiles los llamados periódicos "amarillistas" y las crónicas "rojas" con la desplegada morbosidad ilustrativa de la doxa sobre lo criminal.

A tales normas se le suman la ley 48/1936 que reguló los Estados antisociales y el decreto extraordinario 014/1955 que enfatizó aún más en 
el positivismo penal peligrosista y de defensa social cercano al fascismo. Se superó la tesis clásica en lo que al fin de la pena respecta, porque ya no se buscaba con ella la intimidación, ni la expiación y menos la retribución. Al legislador colombiano de la época le pareció que una manera de prevenir el crimen, era creando los Estados predelictuales, que no son otra cosa que la peligrosidad sin delito; que el hombre es responsable penalmente por el mero hecho de vivir con otros.

La jurisprudencia de la Sala de Casación Penal de la Corte Suprema de Justicia, en sentencia de julio 31 de 1946, se identifica con esa postura doctrinaria:

Todo el que cometa una infracción de la ley penal es responsable, bien se trate de sujetos normales o anormales, cualesquiera sean sus condiciones personales y las objetivas que hayan rodeado el hecho. El concepto de responsabilidad moral que prevalecía en el CP derogado desapareció por completo en la nueva ley. La única diferencia que se establece se relaciona con las consecuencias, pues si el sujeto es normal ha de sufrir la condenación a una pena, si es anormal será sometido a la medida de seguridad que individualmente parezca adaptable a su personalidad. Las penas y las medidas de seguridad tienen un denominador común que es la defensa de la sociedad y que constituyen el medio de lucha contra el delito más directo porque obran una vez se haya manifestado la personalidad del sujeto criminal(CSJ, citada en Nuño, 2002, p. 43).

En este punto, no sobra advertir que según el tratadista en materia penal, Luis Carlos Pérez (1914-1998) (1947) la peligrosidad del delincuente en la legislación colombiana de esa época -aunque se mantiene matizada- no es de suyo, la responsabilidad misma, sino una circunstancia genérica de agravación de la pena al igual que la gravedad del delito, la personalidad del delincuente y los motivos determinantes, porque se olvidó que la peligrosidad es precisamente el resultado de la convergencia de esa triple categoría de factores.

Según Noguera (2003),si se quisieran ver aplicados también estos principios de prevención social en la legislación penal, sin duda alguna, la ley 34/1948 es un claro ejemplo, al prohibir la producción y venta de bebidas fermentadas (derivadas del arroz, maíz, cebada, caña, entre otros) como la chicha a la que se le atribuían los males sociales, el pecado y los delitos. Los motivos para la expedición de esa norma se sustentan en la revuelta popular del "El Bogotazo", el que como se dijo en nota al pie, se originó con el asesinato del líder popular Gaitán el 9 de abril de ese año y que desató una oleada de violencia que las élites asumieron como un peligro por provenir de una masa bárbara y degenerada. La ley en mención, tenía unos fines bien claros:

[por] una parte buscaba tecnificar (higienizar) la fabricación de las bebidas fermentadas, mediante el establecimiento de ciertos procedimientos y estándares industriales; [por otra], pretendió restringir la producción de ciertas bebidas fermentadas, o en otras palabras, favorecer el proceso de producción de ciertas bebidas fermentadas. Todo ello representaba un impulso a la creciente industria cervecera que desde hacía varias décadas venía haciendo esfuerzos por capturar el mercado de la chicha, ayudada, entre otros, por las denuncias de los higienistas contra el "veneno amarillo"(Noguera, 2003, p. 167).

Como se infiere, hay cierto maniqueísmo en la justificación de su expedición, pues si se partía de la convicción higienista que asociaba el consumo de bebidas alcohólicas con la proclividad al pecado y a la delincuencia, no es clara la razón para que se persiguiera la producción y consumo de chicha, por ejemplo, por considerarla un veneno y detonante $\mathrm{y}$, al mismo tiempo, se crearan las condiciones para permitir la fabricación y el consumo de bebidas como la cerveza, producidas más higiénicamente (más sanas que dañinas). Allí se ve que los motivos no fueron solo morales, sino esencialmente económicos. 
Otro ejemplo del control social sobre los cuerpos, se dio en la ciudad de Medellín, cuando por acuerdo del Concejo Municipal 101/1924, se creó la Comisión de Asuntos Sociales (CAS) con la finalidad de vigilar y controlar a los obreros a través de la construcción planificada de viviendas en barrios que garantizaran una vida limpia, sana y en familia con la mujer como garante de ese proceso.

En el elenco de requisitos exigidos para la adjudicación de una vivienda, estaban, entre otros "[...] c. Comprobación certificada de buena conducta moral del solicitante y de sus familiares [...] g. Certificado de médicos graduados sobre la buena salud del peticionario y sus familiares" (reglamento aprobado por la CAS en sesión del 9 de octubre de 1928. Pasó a estudio del Concejo. Archivo Histórico de Medellín. Informes, resoluciones, reglamentos y pedidos, Tomo 520 1931, fol.235; citado en Noguera, 2003, p.145).

Igualmente en Antioquia, en la década de los años treinta del siglo pasado, a instancias del gobierno nacional y ya creada la Secretaría de Higiene y Asistencia Pública, la Asamblea Departamental, fundó en 1935 el Instituto Profiláctico Central de Medellín, rompiendo una larga tradición de énfasis curativo respecto de las enfermedades venéreas y proponiendo estrategias preventivas que garantizaran un "adecuado" comportamiento de las mujeres dedicadas al trabajo sexual como condición de salud para ellas y para sus "clientes", esto es, en definitiva para la sociedad. El canon será "la moral biológica" en remplazo de la moral católica que enfatizaba en el comportamiento pecador de hombres y mujeres.Y amén que las leyes y actos administrativos expedidos serán expresión de esa nueva actitud (Noguera, 2003).

\section{CONCLUSIONES}

A partir de la finalidad de este trabajo, esto es, del análisis de las ideas biologicistas y deterministas de la primera mitad del siglo XX en Colombia, profesadas también por Luis López de Mesa, para inferir cómo circularon y fueron apropiadas, directa o indirectamente en los ámbitos político y jurídico, se presentan las siguientes conclusiones:
En la estrecha relación, ideologizada si se quiere, que se dio en ese periodo histórico entre la ciencia (medicina y biología) y la política, es claro que los médicos fungiendo como legisladores o asesores impusieron un modelo higienista para regenerar la raza colombiana considerada disminuida moral, psíquica y espiritualmente.

Precisamente ese biologicismo determinista, del cual emergió el higienismo tuvo tres orientaciones claras en Colombia:

1. La radical. Que propugnó porque la única estrategia para regenerar la raza era la inmigración que, emulando el proyecto civilizador de pensadores como el argentino Sarmiento (1946), buscaba a través del lavado de cerebro (educación positivista) y la transfusión de sangre (inmigración) una nueva oportunidad histórica para la raza.

2. La moderada. Convencida de que no era a través de la inmigración la manera de reivindicar la regeneración de la raza colombiana, puesto que la causa de esta no era biológica ni genética, sino las condiciones sociales de miseria, desnutrición y falta de higiene.

3. La postura lópezmesiana. Ubicada en un término medio ambiguo, al considerar que es la educación el único instrumento válido que la sociedad tenía para lograr su regeneración. Esta concepción se nutrió conceptualmente del liberalismo político anglosajón, el positivismo cientificista del siglo XIX, el evolucionismo biológico de Spencer (1820-1903) y Spengler (1880-1936) y el idealismo hegeliano.

López de Mesa no habló de degeneración, sino de debilidad y depresión de la raza colombiana que se concretaban para la época en los tres grandes peligros para el país, a saber, la dependencia a Estados Unidos, la insuficiente educación y la pobreza. Inicialmente inclinado por la inmigración, dio un giro hacia la estrategia del poblamiento, pero que a la postre tampoco funcionó, porque en Colombia la inmigración pese a tener la disposición gubernamental para que se diera, no logró atraer ciudadanos de otros países como 
sí ocurrió, por ejemplo, en Brasil y Argentina. Y el poblamiento tampoco logró sus frutos, entre otros motivos, por la fragmentación del territorio atravesado por tres cordilleras.

Más allá de estas tres posturas, en el debate sobre la raza en Colombia, subyacen otros motivos que a simple vista no son tan notorios. Razones de índole biopolítico (la intención de higienizar y medicalizar a la población) para que la sociedad y el Estado colombiano pudieran dar respuesta desde la "ciencia" a las demandas que el entorno mundial y nacional les hacían principalmente en materia económica.

Las estrategias biopolíticas utilizadas gracias a los consejos de los higienistas se tradujeron en una larga serie de normas jurídicas que regularon materias educativas, sanitarias y penales, todas con una única finalidad de castigar o en el mejor de los casos, prevenir comportamientos desviados. Así la cuestión social, se convirtió en un asunto estatal, puesto que es al Estado y solo a él, a quien competía reorientarla educación del hombre colombiano.

En ese espectro se pudieron ver rupturas como la ocurrida en la década de 1930, cuando la instauración de la República liberal puso fin al periodo de la hegemonía conservadora, consiguiendo la separación entre lo laico y lo religioso, plasmado en el lema del primer periodo presidencial de Alfonso López Pumarejo (la "Revolución en Marcha").

López de Mesa como un convencido de que la raza debía ser culturizada, enfatiza en casi toda su obra en el papel que la educación debía asumir en el proceso de desarrollo individual y social como cohesionadora por medio de valores compartidos. En esa vía su Programa de Educación Aldeana se sirvió de un medio de comunicación masivo como la radio para alcanzarlos propósitos perseguidos de reeducar a la población, para evitar la catástrofe. Esto se logró mediante su paso fugaz por el Ministerio de Educación y luego como miembro y asesor del gobierno de Eduardo Santos que continuó la línea legislativa y administrativa de López Pumarejo.
En esa preocupación por la raza y ante el evidente fracaso de las políticas inmigratoria, de poblamiento y de solución definitiva de los problemas económicos y sociales de la población, el Estado tuvo que asumir un interés marcado por la infancia, pues era ella, a través de un control efectivo en el ámbito escolar y familiar la que podría regenerar la raza.

Educar al niño física, psíquica y espiritualmente, era poner fin a los largos avatares que el hombre colombiano había padecido. En este punto el paso de una moral católica a una biológica fue decisivo, puesto que los médicos hicieron caer en la cuenta de que la acción humana no estaba guiada por la voluntad, sino por factores como la herencia y el medio geográfico; por lo que, si estos eran intervenidos, se podía garantizar un nuevo tipo de hombre.

Desde esta perspectiva se entiende la historia legislativa de la salubridad y el higienismo de la primera mitad del siglo XX colombiano, ya que de una predisposición a lo curativo, se pasó a la profilaxis como canon para asumir la cuestión social desde lo educativo, lo sanitario e incluso lo penal.

Las leyes penales expedidas en la década de los treinta y siguientes, se apropiaron de los postulados del peligrosismo y la teoría de la defensa social, haciendo hincapié en la personalidad del delincuente, en lo que este pudiera llegar a hacer y no necesariamente en lo que finalmente hiciera. Por lo mismo, el higienismo determinista en Colombia se plasmó política y legislativamente de variadas formas y en reiteradas oportunidades. El Código Penal de 1936,el Código de Procedimiento Penal de 1938 y las normas precedentes sobre el control de las enfermedades venéreas y las luchas antialcohólicas, sobre todo en las ciudades de Bogotá y Medellín, son una muestra de ello.

En concreto, en la ciudad de Medellín la profilaxis se convirtió en el modelo higienista por antonomasia, puesto que el acento se hizo en la prevención por medio de la educación de la actitud ante la propia salud y lo que implica cuidarla personal, social y estatalmente. 
Por último, se observa el biologicismo y el higienismo como estrategias biopolíticas de ayer en el contexto de hoy, se podría entender que la salud de la población sigue siendo un asunto de primer orden, en donde la prevención desempeña un papel esencial. La Declaración de Yakarta, por ejemplo, sigue esta ruta, puesto que cada individuo debe hacerse responsable de su propia salud, con lo cual, el modelo de la medicina preventiva se impone política, económica y socialmente al modelo de la medicina curativa.

Asuntos como el trasplante de órganos, la clonación de seres humanos, el diagnóstico genético preimplantacional, la interrupción voluntaria del embarazo, la eutanasia, la fecundación in vitro, la muerte encefálica, entre otros, bien podrían mirarse desde esta perspectiva biopolítica, porque si cada uno, según su predisposición genética y hábitos de vida, asume su salud como un asunto neural, se puede minimizar los riesgos que comportan tales prácticas. $\mathrm{O}$ visto de otra forma, cómo toman el Estado y la sociedad en general, el control político de la vida.

\section{REFERENCIAS}

Carranza, R. \&Barrientos, J. (1981). Luis López de Mesa. Obras selectas. Pensadores políticos colombianos. Bogotá: Cámara de Representantes.

Castro-Gómez, S. (2007). ¿Disciplinar o poblar? La intelectualidad colombiana frente a la biopolítica (1904-1934). Nómadas, 26, 44-55.

Foucault, M. (1989). Historia de la sexualidad. I. La voluntad de saber. México D. F.: Siglo Veintiuno Editores.

Foucault, M. (1992). Genealogía del racismo. Madrid: La Piqueta.

García, C. (2006). El trinomio verdad-biopolíticaderecho en el contexto europeo del siglo XVIII y sus posteriores repercusiones. Cuadernos de Derecho, 2, 83-96.

Gutiérrez, M. (2010). Proceso de institucionalización de la higiene: estado, salubridad e higienismo en Colombia en la primera mitad del siglo XX. Estudios Socio-Jurídicos, 12(1), 73-97.

Hegel, F. (1970). Lecciones de filosofía de la historia universal. Barcelona: Zeus.

López de Mesa, L. et al. (1920).Los problemas de la raza en Colombia. "Tercera conferencia". Bogotá: El Espectador, 1920, p. 144.

López de Mesa, L. (1926a). Los problemas de la raza en Colombia. Bogotá: El Espectador.

López de Mesa, L. (1926b). Civilización contemporánea. París: Agencia Mundial de Librería.

López de Mesa, L. (1970). Disertación sociológica. Medellín: Bedout.

Martínez, A. (1986). Escuela, maestro y métodos en Colombia 1750-1820. Bogotá: Universidad Pedagógica Nacional de Colombia.

Melo, J. (1985). Proceso de modernización en Colombia, 1850-1930. Revista de Extensión Cultural, Universidad Nacional,20, 31-41.

Ministerio de Educación Nacional. (1940). La obra educativa del gobierno. Bogotá.

Noguera, C. (2003). Medicina y política. Discurso médico y prácticas higiénicas durante la primera mitad del siglo XX en Colombia. Medellín: Universidad Eafit.

Nuño, J. (2002).Sistema penal y control social en Colombia. Tesis para optar al título de abogado. Bogotá: Pontificia Universidad Javeriana.

Ocampo, J. (2007).Carlos Arturo Torres (18671911).En S. Castro-Gómez, A. Flórez-Malagón, G. Hoyos Vásquez\&C. Millán de Benavides. Pensamiento colombiano del siglo XX.(Eds). (pp. 109-129). Bogotá: Editorial Pontificia Universidad Javeriana.

Pérez, L.(1947). Nuevas bases del derecho criminal. Bogotá: ABC. 
Quevedo, E, et al. (2004). Café y gusanos, mosquitos y petróleo. Bogotá: Universidad Nacional de Colombia.

Sáenz, J., Saldarriaga, O. \&Ospina, L. (1997). Mirar la infancia: pedagogía, moral y modernidad en Colombia, 1903-1946. Tomo I. Medellín: Colciencias, Ediciones Foro Nacional por Colombia, Ediciones Uniandes y Editorial Universidad de Antioquia.

Sarmiento, D. (1946).Conflicto y armonía de las razas en América. Buenos Aires: Intermundo.

Silva García, G. (2009). La construcción social de la criminalidad en Colombia y en América
Latina. Ponencia en el X Congreso Nacional de Sociología Jurídica, Córdoba-Argentina.

Uribe, C. (2007). Luis López de Mesa (18841967). En S.Castro-Gómez, A. Flórez-Malagón, G. Hoyos Vásquez\& C. Millán de Benavides. Pensamiento colombiano del siglo XX.(Eds). (pp. 363-401). Bogotá: Editorial Pontificia Universidad Javeriana.

Villegas, A. (2005). Raza y nación en Luis López de Mesa. Análisis Político, 26, 209-232.

Zea, L. (1978).Filosofía de la historia americana. México D. F: Fondo de Cultura Económica. 